\title{
O GERENCIAMENTO DE REQUISITOS DE DESEMPENHO NO PROCESSO DE PROJETO
}

\author{
Paola Nicolai $^{(1)}$, André Cardoso ${ }^{(1)}$, Beatriz Kase ${ }^{(1)}$, Flávia Souza ${ }^{(1)}$ \\ (1) Universidade de São Paulo, São Paulo
}

\begin{abstract}
Resumo
O efetivo atendimento a norma brasileira NBR 15.575:2013-Edificações HabitacionaisDesempenho é complexo, não só pelo conteúdo técnico, mas também por abranger todo o ciclo de vida do edifício e diversos agentes da cadeia produtiva. A Modelagem da Informação da Construção (BIM) traz novos processos e tecnologias que possuem grande potencial para melhorar o atendimento a requisitos de desempenho na construção civil. Pode-se apontar o seu próprio uso no desenvolvimento e coordenação de projetos, mas destaca-se a utilização de ferramentas de checagem de dados no modelo, capazes de verificar a conformidade do projeto diante de regras pré-estabelecidas. Nesse contexto, questiona-se quais são os critérios normativos cujos atendimentos mais dependem do projeto e o quanto a indústria está familiarizada com as respectivas soluções BIM. Assim, através de uma Survey realizada com profissionais de empresas do setor da construção civil, o artigo expõe um diagnóstico sobre a percepção de gestores e projetistas em relação ao gerenciamento de requisitos de desempenho, além de apresentar dados gerais sobre o nível de utilização de metodologias e ferramentas da Modelagem da Informação da Construção dentro desta aplicação.
\end{abstract}

\section{Introdução}

A norma NBR 15.575 - Edificações Habitacionais - Desempenho, cuja última versão foi lançada em 2013, vem transformando o modo como os projetos residenciais brasileiros estão sendo elaborados e produzidos ao orientar os mesmos a cumprir requisitos de desempenho [10]. Isto porque, além de colocar o conceito de desempenho em pauta, até então pouco discutido, o documento não prescreve como fazer, mas sim qual é o comportamento em uso que os sistemas que compõem a construção precisam ter. Assim, tornou-se um verdadeiro marco para o setor da construção civil brasileiro.

Por abranger todo o ciclo de vida do edifício, a norma atinge não só coordenadores e projetistas, mas também construtores e fornecedores. Cada interveniente da construção, de acordo com a 
NBR 15.575, possui uma incumbência técnica clara, formando assim, uma cadeia de responsabilidades para o atendimento final às exigências dos usuários.

Ao analisar o processo de projeto na atualidade, é impossível não esbarrar nas discussões voltadas ao conceito da Modelagem da Informação da Construção como metodologia para a prática projetual, comunicação e troca de informações entre as diversas partes envolvidas. As vantagens da utilização do BIM vão além da representação dos dados, mas também no ganho de eficiência ao trabalhar com informações disponibilizadas pelos modelos e assim, o processo de decisão é baseado cada vez mais em representações digitais da construção [3]. Avaliações incorretas de projetos quanto à conformidade de determinadas características afetam negativamente o desempenho de edifícios e pode levar a erros com alto custo de correção [12]. Assim, pode-se considerar que o BIM se caracteriza como uma abordagem de grande potencial para auxiliar os gestores ao atendimento à norma NBR 15.575.

Diante deste cenário, os coordenadores, dentro do seu escopo de atuação, precisam compreender a cadeia de responsabilidades impactada pela norma de desempenho para tomarem as melhores decisões em relação às soluções propostas nos projetos, incentivando as melhores práticas entre todas as disciplinas e fazendo uso de metodologias que elevam a qualidade do desenvolvimento do processo de projeto, como o BIM. Desta forma, o trabalho tem como principal objetivo o levantamento da perceção de coordenadores e projetistas do setor da construção civil brasileiro em relação ao gerenciamento de requisitos de desempenho, além das tecnologias e ferramentas utilizadas no processo de projeto. $\mathrm{O}$ artigo está sendo desenvolvido por pesquisadores da linha de pesquisa voltada à Gestão de Projetos do Mestrado Profissional em Inovação na Construção Civil da Escola Politécnica da Universidade de São Paulo, estando dentro do contexto da pesquisa de mestrado "A gestão de requisitos de desempenho no processo de coordenação de projetos com o auxílio do BIM”.

\section{Revisão Bibliográfica}

\subsection{ABNT 15.575}

A discussão em torno do conceito de desempenho no Brasil surgiu principalmente a partir da década de 80, quando se observou um considerável déficit habitacional no país. Com o cenário favorável à construção de edifícios residenciais, as empresas passaram a adotar novas técnicas construtivas sem controle tecnológico, o que estimulou diversos debates para que critérios mínimos de desempenho para esta tipologia fossem estabelecidos. Grupos de pesquisas com profissionais do setor foram formados, acarretando na futura elaboração do documento normativo, que teve sua publicação realizada somente em 2013. A NBR 15.575 se diferencia da maior parte das normas brasileiras por não apresentar um caráter prescritivo [10]. De fato, este regulamento preconiza níveis de desempenho que os sistemas do edifício devem possuir, independentemente dos materiais ou componentes que forem especificados e utilizados em sua produção. Dividida em seis partes, a norma apresenta parâmetros relacionados à segurança, habitabilidade e sustentabilidade, focando no comportamento em uso da edificação. Além disso, o documento referência outros 255 regulamentos técnicos, tornando-se assim, um dos principais códigos voltados para construções habitacionais no Brasil [4].

Ao incorporador, de acordo com a norma, cabe a identificação dos principais riscos na fase de projeto e fornecer tais informações aos projetistas. O construtor deve elaborar o manual de operação, uso e manutenção, abordando cuidados de utilização. A norma determina que os 
fornecedores de materiais, componentes e sistemas devem ser capazes de caracterizar o desempenho de seus produtos. Por sua vez, os usuários devem realizar as devidas manutenções no empreendimento. Finalmente, aos projetistas cabe a especificação de todos os materiais e componentes da construção, devendo especificar a vida útil de projeto de todas as partes que compõem a edificação. Desta forma, percebe-se que projetistas e os seus respectivos coordenadores são protagonistas, pois determinam as soluções técnicas que irão orientar a construção, mas o alcance efetivo dos resultados de desempenho depende da ação de outros atores que não estão diretamente inseridos no processo de projeto.

\subsection{Requisitos e a modelagem da informação da Construção}

Segundo Eastman et al. [2], a Modelagem da Construção da Informação (BIM) está alterando o modo como enxergamos os edifícios, sendo um dos mais promissores desenvolvimentos para a indústria AEC. De acordo com mesmos autores, com o BIM é possível ter um modelo virtual preciso de uma edificação, contendo a sua geometria exata e diversos dados relevantes para suportar a construção, a fabricação e aquisição de insumos.

Os benefícios da Modelagem da Informação da Construção são consideravelmente reconhecidos em todas as fases de um empreendimento: visualização antecipada, consistência de informações, maior precisão na estimativa de custos, melhora do trabalho colaborativo, entre tantos outros que contribuem, consequentemente, para construções com maior qualidade. Neste contexto, os processos são os mais afetados, já que alcançar estes benefícios envolve mudanças significativas em relação às práticas consideradas tradicionais, onde o relacionamento entre diferentes agentes e a coordenação das atividades muitas vezes é ineficiente.

Assim, uma vez que a premissa é garantir, da melhor maneira possível, o atendimento aos critérios de desempenho preconizados pela NBR 15.575, o coordenador de projetos passa a ter maior munição para cumprir a tarefa com os processos e ferramentas BIM, pois vão facilitar uma visão mais sistêmica do empreendimento, fomentar a colaboração e comunicação com diferentes a gentes, além de melhorar a verificação de projetos para este fim. Dentro do planejamento das atividades estratégicas do processo de projeto, são definidas as ferramentas necessárias para viabilizar os usos do BIM pretendidos. Pode-se apontar mais de um uso que pode auxiliar, mesmo que indiretamente, no maior atendimento a requisitos de desempenho, como é o caso do Desenvolvimento de Projetos e a Coordenação 3D. Contudo, uma das grandes oportunidades que surgem neste contexto é a checagem de conformidade do projeto, isto é, a avaliação mais precisa se ele cumpre certos critérios estabelecidos.

Arto Kiviniemi [1] afirma que um simples link entre requisitos e softwares de modelagem pode aumentar a gestão de necessidades dos clientes ao longo de todo o processo. Atualmente, a revisão do modelo é feita manualmente, consumindo tempo da equipe e tornando-se mais suscetível a falhas humanas [13]. Traduzir uma linguagem legível para pessoas em um formato que o computador consiga interpretar exige um processo lógico de criação de regras, aspeto fundamental para se trabalhar com análises automáticas em projetos com um modelo BIM [6]. Ainda não está disponível uma representação padrão para códigos regulatórios de edifícios [12], mas a checagem de dados e requisitos em um modelo já é a proposta de algumas ferramentas disponíveis no mercado (ex.: dRofus, Solibri Model Checker, etc.), caracterizando-se como importantes oportunidades para a verificação e controle de critérios de desempenho, mesmo com certas limitações.

Outra possibilidade que se abre é realizar essas inspeções do modelo a partir do formato IFC. Segundo Luo e Gong [7], um primeiro obstáculo para a checagem automática é que softwares 
BIM possuem os seus próprios formatos autorais e a utilização de API (Application Programming Interface) é limitado para este propósito. Desta forma, estes mesmos autores argumentam que o IFC é a única representação neutra e independente da construção, suportada pela maioria destas ferramentas.

\section{Método}

Como dito anteriormente, o objetivo do artigo é apresentar um diagnóstico. Espera-se responder as seguintes questões: Qual é o nível de conhecimento dos profissionais de projeto do setor da construção civil em relação ao conteúdo da norma? Quais são os requisitos que eles consideram mais gerenciáveis na fase de projeto? O BIM já é utilizado por esses profissionais para auxiliar nesta tarefa? Responder estas perguntas é importante para embasar propostas que integrem o gerenciamento de requisitos de desempenho com a Modelagem da Informação da Construção, quais podem ser os possíveis entraves e as capacidades técnicas que os profissionais de projeto precisam desenvolver para que isto ocorra.

Por se tratar de um trabalho com aspeto investigativo, optou-se pela elaboração e aplicação de um questionário padrão, utilizando o método Survey, para atingir o objetivo proposto. O intuito deste método é produzir descrições quantitativas sobre "o que está acontecendo?" ou "como e por quê?" em relação a fenômenos presentes ou no passado recente [5], e que é descrito por Visser; Krosnick e Lavrakas [11] como o método que trata do levantamento de dados de uma amostra de elementos representativos de uma população bem definida, através de um questionário. Neste estudo, o questionário foi enviado para profissionais do setor da construção civil brasileira, mais especificamente para arquitetos e engenheiros envolvidos com o desenvolvimento de projetos arquitetónicos, estruturais e de instalações prediais. A principal base dos inquiridos veio de cursos de especialização e pós-graduação de gestão de projetos da Universidade de São Paulo, que possui profissionais de todo o país.

O questionário foi elaborado após discussões prévias com agentes envolvidos com os conceitos da Norma de Desempenho (NBR 15.575 - Edificações Habitacionais - Desempenho); a análise dos dados coletados permitiu as conclusões aqui apresentadas. A Figura 1 resume as atividades conduzidas para elaboração deste estudo.

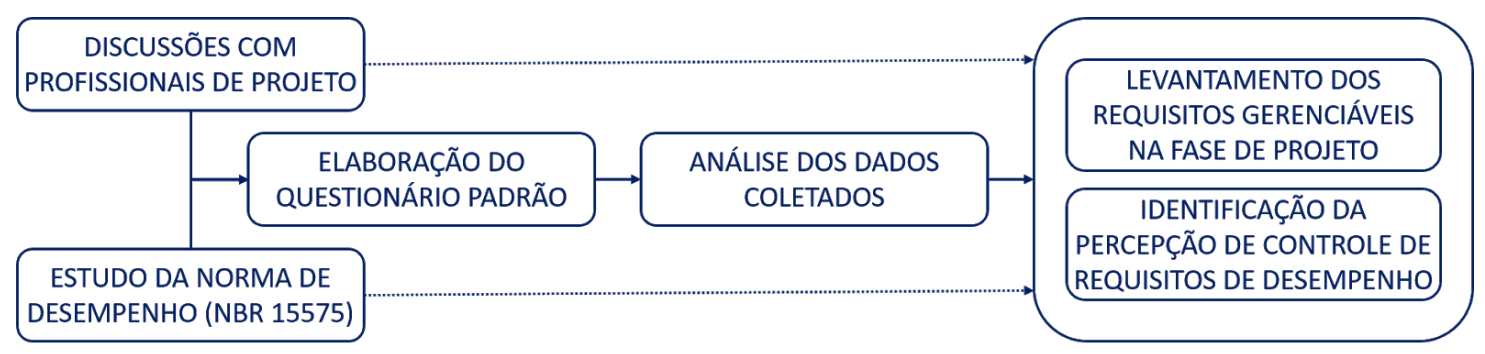

Figura 1: Método de trabalho.

\section{Dados Coletados e Discussão}

O questionário foi respondido em sua totalidade por 41 profissionais, predominantemente com menos de 40 anos de idade, formação em arquitetura e/ou engenharia civil, e atuação em 
empresas de projeto e/ou construção, como projetistas ou coordenadores (gerentes), tal como ilustrado na Figura 2.
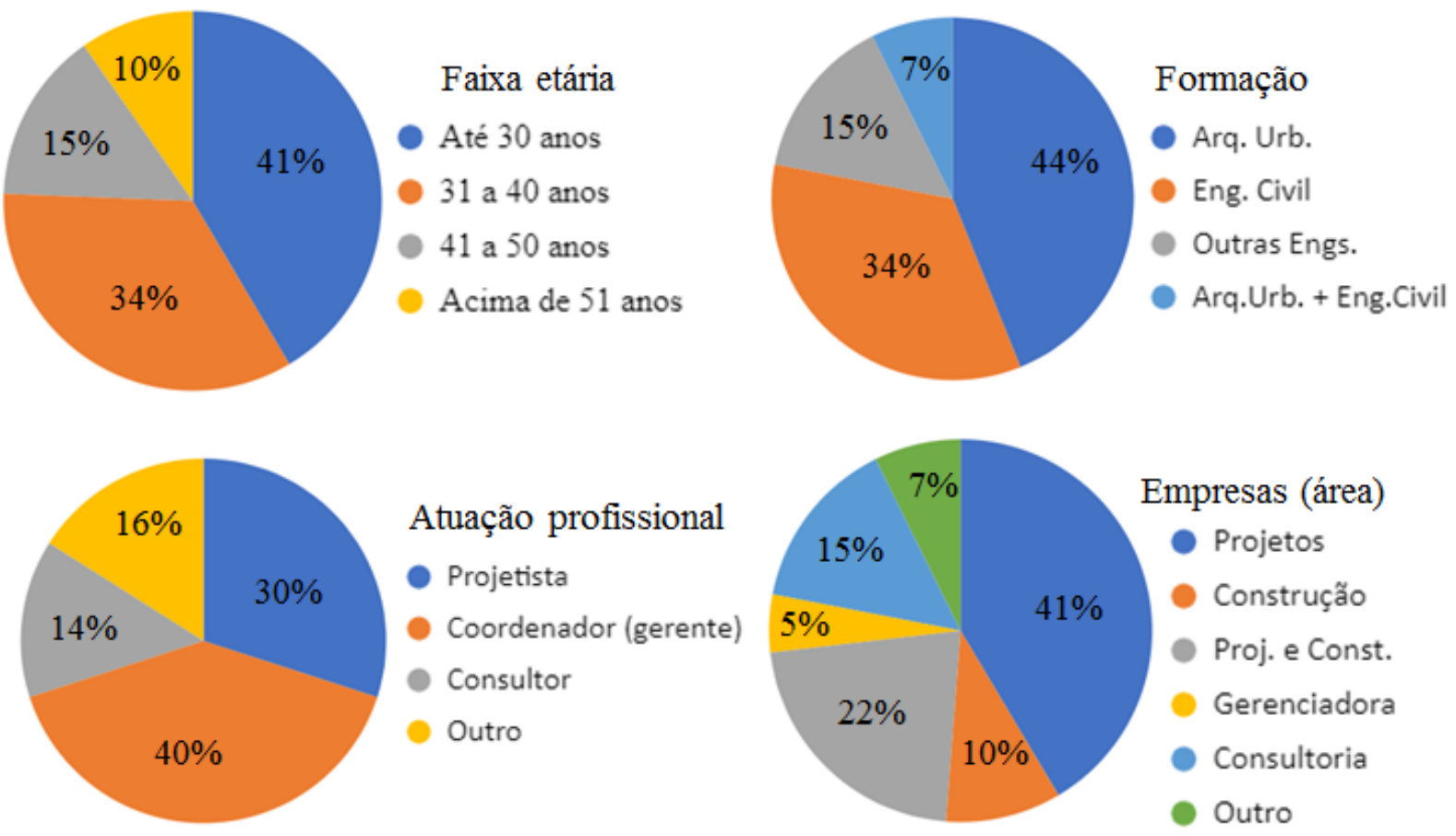

Figura 2: Amostra da pesquisa.

Considera-se que esta amostra seja representativa, uma vez que engloba profissionais que atualmente trabalham com as mais variadas disciplinas e segmentos, tal como identificado na Figura 3, a seguir.
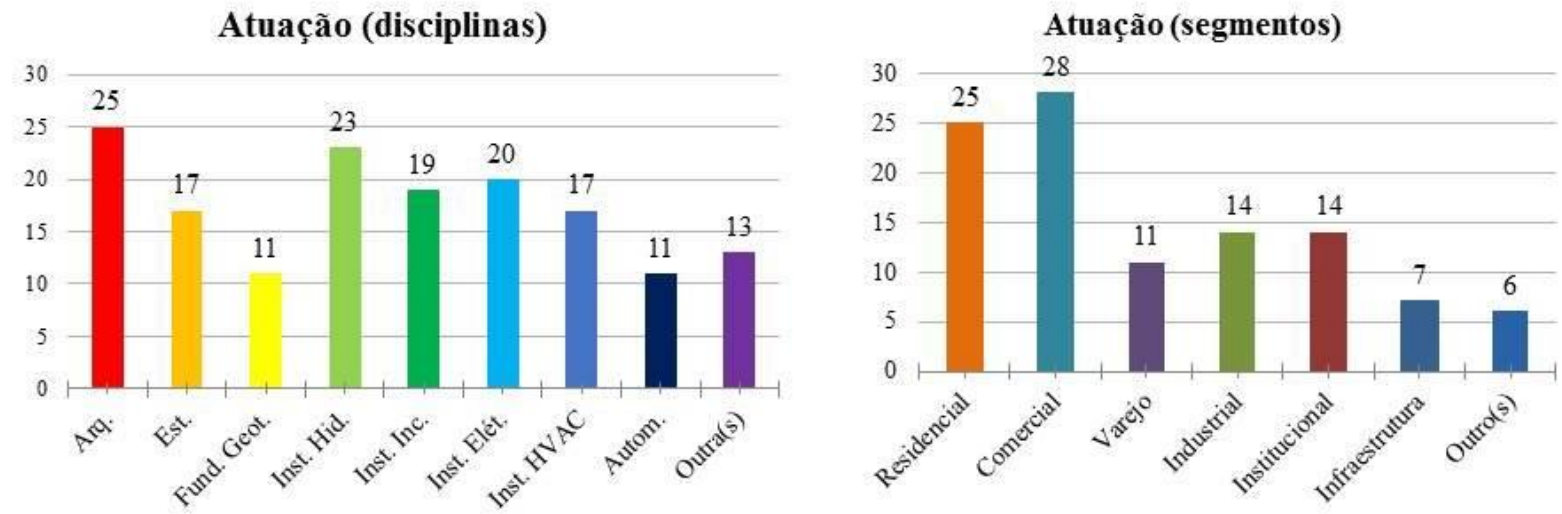

Figura 3: Atuação dos respondentes.

Quanto à NBR 15575, os profissionais foram questionados sobre: seu conhecimento a respeito da norma, atribuindo uma nota de 0 (nenhum conhecimento) a 5 (muito conhecimento); e, dentre aqueles que indicaram participação em projetos residenciais, se os requisitos de desempenho são considerados em suas atividades (Figura 4). 
P: De 0 a 5 , qual é o seu conhecimento sobre a Norma de Desempenho NBR 15575:2013?

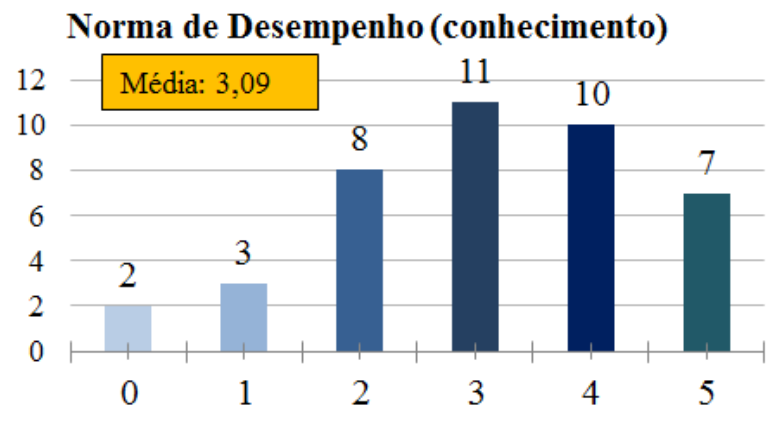

P: No desenvolvimento de projetos residenciais, a empresa em que você atua considera os requisitos de desempenho abordados pela NBR 15575:2013?

\section{Requisitos de desempenho (adoção)}

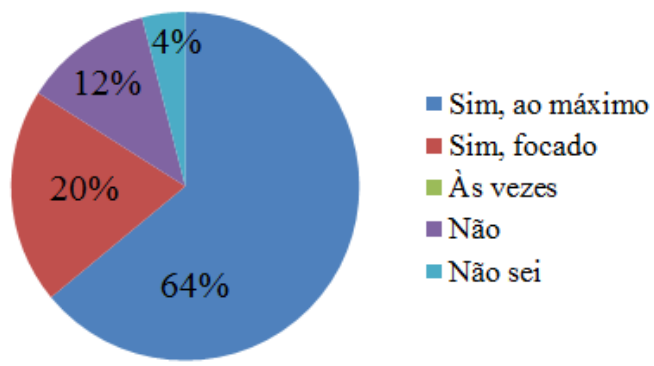

Figura 4: Conhecimento sobre a NBR 15575 e consideração de seus requisitos.

Destaca-se que existe um conhecimento médio em relação à norma de desempenho, com média de 3,09 pontos. As pessoas que afirmaram ter um conhecimento bom (04 pontos) à avançado (05 pontos) atuam em sua maioria como coordenadores (07 respostas) e são engenheiros civis (08 respostas). Vale ressaltar também que os 02 respondentes que apontaram nenhum conhecimento atuam como projetistas, cuja média específica de conhecimento ficou em apenas 2,66. Embora uma limitação exista, identifica-se que $64 \%$ apontaram que abordam todos os requisitos que estão dentro do seu escopo. Com relação ao BIM, os profissionais foram indagados sobre a utilização de suas tecnologias, e sobre a adaptação de processos, o principal contexto de utilização das ferramentas e a checagem de requisitos através de modelos. As respostas se encontram na Figura 5 e 6, a seguir.

\section{P: A empresa em que você atua utiliza tecnologias do BIM?}

\section{Tecnologias BIM(uso)}

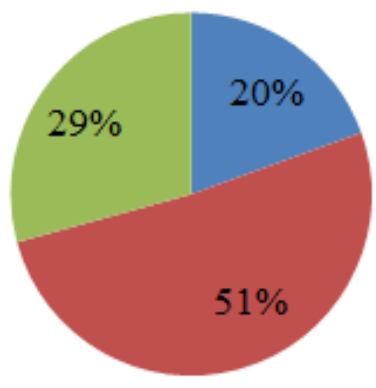

P: A empresa em que você atua já adaptou seus processos ao BIM?

Processos BIM (adaptação)

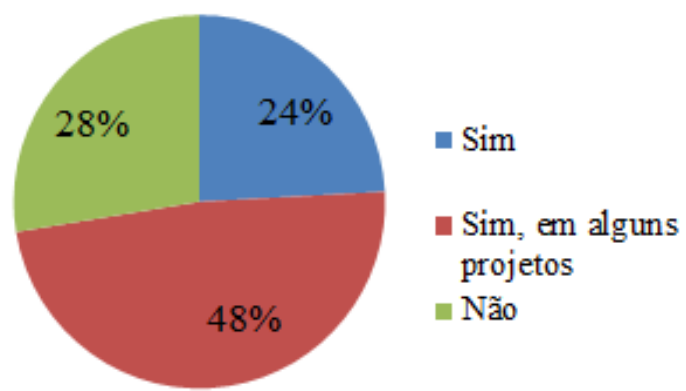

Figura 5: BIM: tecnologias e processos. 
P: Em que contexto são utilizadas tecnologias BIM?

Tecnologias BIM(uso principal)

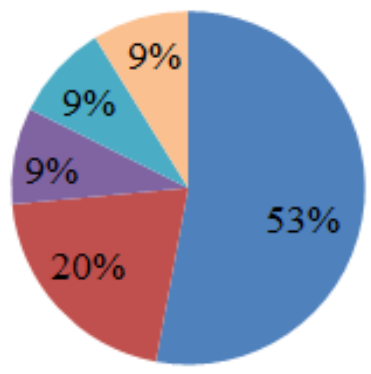

- Modelagem

- Visualização

- Comcercial

- Clash detection

- Planejamento

Gestão de requisitos

Outro (s)
P: A empresa utiliza alguma ferramenta BIM com o intuito de checar requisitos no modelo?

BIM para checagem de requisitos

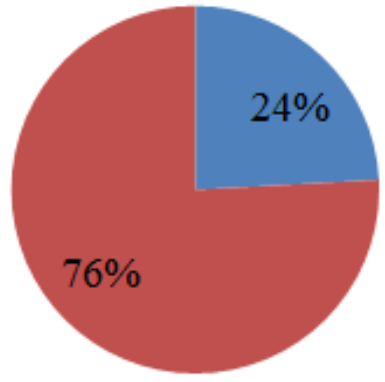

Figura 6: BIM: uso principal e gestão de requisitos.

O BIM está presente, de alguma forma, nas atividades da maioria dos profissionais, mas apenas $20 \%$ da população relataram que utilizam a Modelagem da Informação da Construção em todos os projetos (tecnologia). Dentro da amostra dos $20 \%$, não se observa nenhum perfil claro das empresas em que os respondentes trabalham, sendo estas de variados portes (grande, médio, micro), de diferentes disciplinas (arquitetura, estrutura e instalações prediais) e que atuam em diferentes ramos do mercado (residencial, comercial, industrial, etc.). O grande contexto de utilização do BIM ainda é a modelagem e poucas empresas adaptaram os seus processos à este conceito (24\%), enquanto $76 \%$ afirmaram não utilizar ferramentas para a checagem de requisitos no modelo. É interessante notar que todas as pessoas que afirmaram sempre utilizar tecnologias da Modelagem da Informação da Construção em seus projetos, apontaram que suas empresas adaptaram os processos ao BIM também.

Aprofundando a temática da Norma de Desempenho, os profissionais foram questionados sobre o grau de dificuldade em atendê-la sob quatro aspetos. Na Figura 7, constam as respostas dadas a esse item.

P: De 0 a 5 , indique o grau de dificuldade para o atendimento à NBR 15575 dos aspectos a seguir.

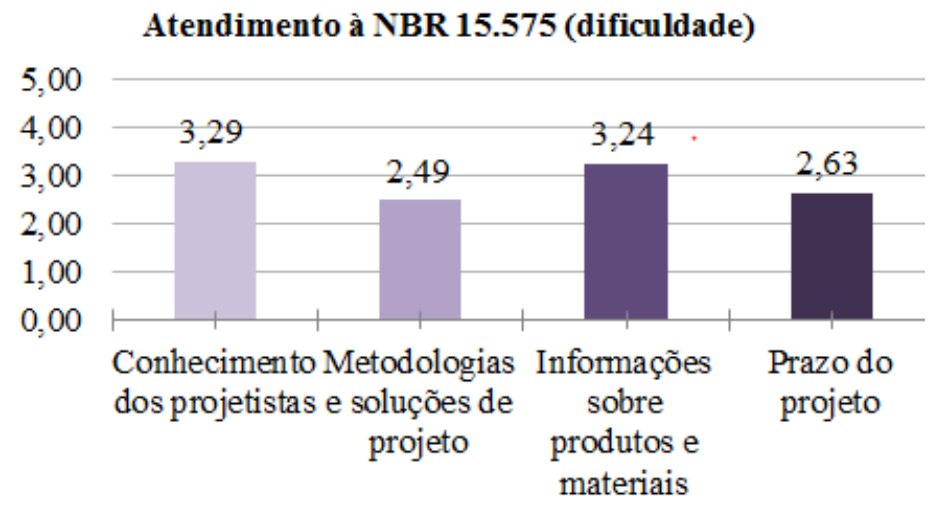

Figura 7: NBR 15575: Dificuldades e análise de riscos.

Com relação às dificuldades no atendimento aos requisitos da norma de desempenho, todos os itens questionados receberam, em média, um grau mediano de complexidade, com destaque 
para o conhecimento dos projetistas e o acesso à informações técnicas sobre os produtos e componentes de fornecedores. Por fim, a última parte do questionário pedia aos respondentes a atribuição de notas, numa escala de 0 a 5, que correspondem ao impacto de cada um dos agentes identificados no alcance dos grupos de requisitos elencados de acordo com a NBR 15575, sendo a nota 0 atribuída a nenhum impacto e a nota 5 a muito impacto. Por exemplo, se o respondente considerasse que as atividades do construtor tivessem muito impacto no desempenho estrutural, ele atribuiria a nota 5 neste caso. A Figura 8 apresenta as notas médias atribuídas pelos respondentes a cada agente, em cada um dos grupos de requisitos.

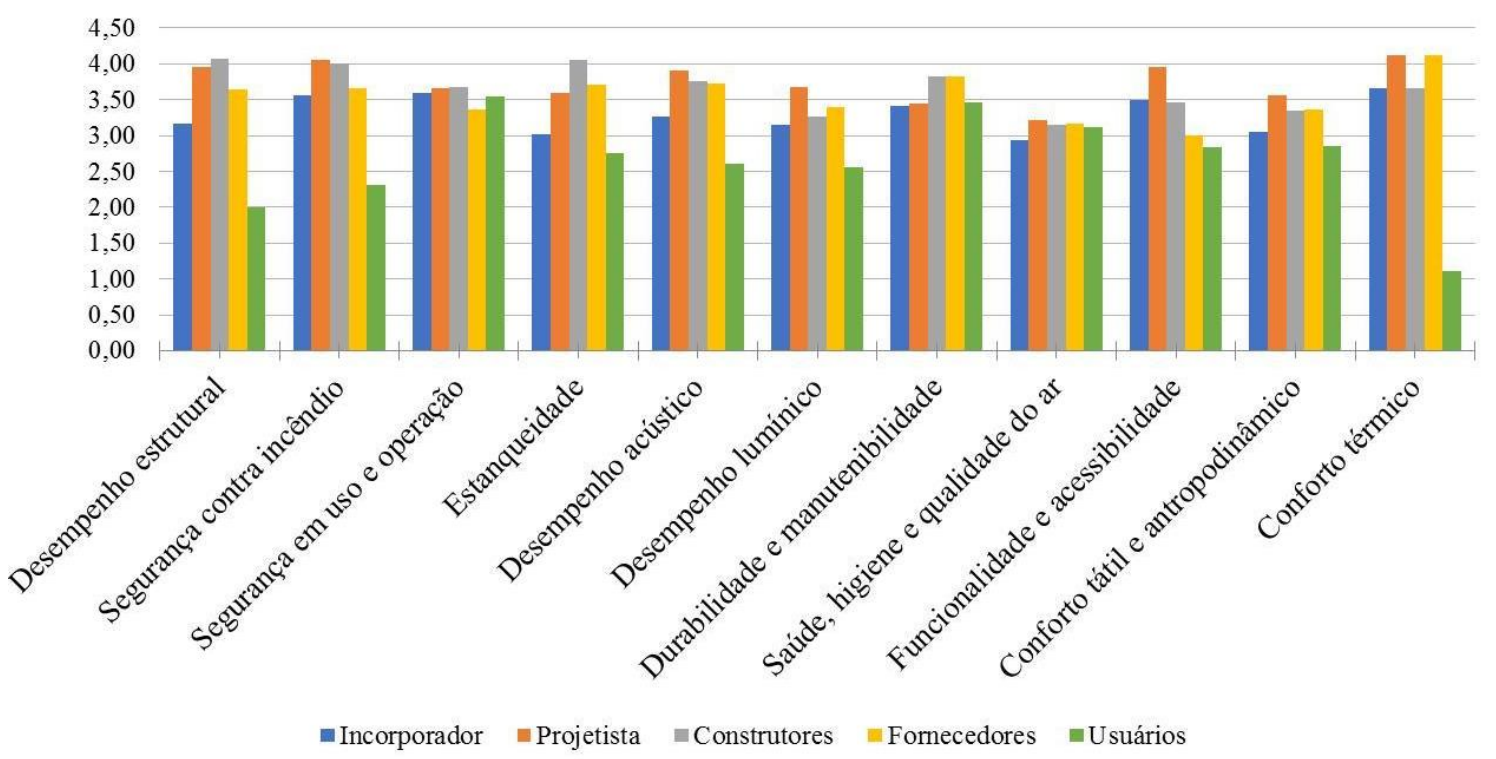

Figura 8: Agentes vs Grupos de Requisitos.

De uma forma geral, o resultado demonstrou que a influência de todos os agentes está bem próxima em praticamente todos os grupos de requisitos, com as maiores diferenças encontradas com os usuários em alguns itens. Ao entrar especificamente dentro de cada grupo de requisitos elencado pela NBR 15.575, é possível elencar quais possuem mais e menos dependência dos projetistas, segundo a percepção dos respondentes, sendo que "desempenho estrutural", "estanqueidade" e "durabilidade e manutenibilidade" são os grupos onde o projeto não aparece com os maiores índices, embora a diferença seja pequena, destacando-se construtoras e/ou fornecedores nesses casos.

\section{Conclusão}

Para além dos resultados diretos de cada questão, os dados levantados pela Survey permitiram realizar análises trasnversais importantes. O primeiro cruzamento que se destaca é o fato de que 64\% afirmam atender ao máximo o código regulatório, mas a maioria apresenta um conhecimento técnico regular da mesma. Pode-se questionar, a partir desta distorção, o quão de fato esses profissionais estão atendendo a norma de desempenho e se ressalta a importância de capacitar melhor os projetistas neste contexto. Além disso, o presente diagnóstico permitiu confirmar que, segundo os respondentes, o efetivo atendimento à praticamente todos os 
requisitos de desempenho, de maneira geral, não é resultado apenas do projeto, isto é, há a dependência da qualidade das atividades dos demais intervenientes, assim, pode-se concluir primeiramente a importancia de uma comunicação adequada entre o coordenador de projetos com os demais participantes do empreendimento.

Com a Survey, foi possuivel diagnosticar que o nível de maturidade da Modelagem da Informação da Construção no setor ainda é inicial, principalmente pelo baixo índice de implantação de processos nas empresas da construção civil. O fato do BIM ainda não ser utilizado em todos os projetos, mesmo nas organizações onde estes conceitos já se fazem presentes, pode apontar condições externas ainda heterogêneas, como formas de contratação e diferentes níveis tecnológicos de parceiros no mercado. Até este ponto, pode-se considerar que era um cenário já conhecido no meio acadêmico. Contudo, pode-se averiguar que a adoção de ferramentas ainda está condicionada à modelagem e pouco foi explorado pelos profissionais com relação ao potencial que essas tecnologias possuem no gerenciamento de requisitos de desempenho. $\mathrm{O}$ fato de terem tido respondentes que afirmaram que suas empresas já adaptaram os seus processos ao BIM, mas ainda checam os seus modelos de forma visual, levanta a questão sobre a qualidade destes processos e se essas ogranizações realmente entenderam o que esta metodologia envolve. Dentro deste contexto, as ferramentas que foram apontadas pela amostra quando questionadas sobre a checagem de características de projeto são reconhecidas principalmente como soluções para a revisão do modelo em busca de interferencias, devendo ser melhor investigado como e até que ponto de fato identificam requisitos técnicos da norma de desempenho em uma representação digital de uma construção.

Como dito anteriormente, esta Survey está inserida em uma pesquisa em desenvolvimento, onde se pretende propor processos para profissionais conseguirem gerenciar requisitos de desempenho com o auxílio da Modelagem da Informação da Construção. Sabe-se que o campo da tecnologia está avançado e algumas aplicações, como a checagem automática, são promissores para a sinergia entre estes dois univeros, mas os resultados expostos por este diagnóstico revelam que a indústria da construção civil brasileira ainda precisa se apropriar destas ferramentas disponíveis e ir além da modelagem, uso já bastante desenvolvido e conhecido. Nesse sentido, os caminhos futuros apontam que profissionais de projeto, além de precisarem aumentar o conhecimento do conteúdo técnico da norma, precisam desenvolver habilidades tecnológicas para as utilizarem em prol das suas necessidades e conseguir, assim, viabilizar a estruturação de processos mais eficientes, capaz de envolver os diversos agentes da cadeia produtiva.

\section{Referências}

[1] A. Kiviniemi, "Requirements Management Interface to Building Product Models", Tese de Doutoramento, Stanford, Departamento de Engenharia Civil e Ambiental da Universidade de Stanford, EUA, 2005.

[2] C. Eastman, P. Teicholz, R. Sacks, K. Liston. "Manual de BIM: um guia de modelagem da informação da construção para arquitetos, engenheiros, gerentes, construtores e incorporadores”. Editora Bookman, 2014. 
[3] C. Preidel, S. Daum, Borrmann, A. "Data retrieval from building information models based on visual programming", Visualization in Engineering, 5:18, Novembro 2017. doi: 10.1186/s40327-017-0055-0

[4] F. Silva, E. Arantes, "Verificação automática de requisitos de projetos da norma de desempenho NBR 15.575 a partir da adequação de regras da plataforma BIM Solibri Model Checker", in: $1^{\circ}$ Simpósio Brasileiro de Tecnologia e Comunicação na Construção e $10^{\circ}$ Simpósio Brasileiro de Gestão e Economia da Construção (2017), Fortaleza, Ceará, BRA, 2017

[5] H. Freitas, M. Oliveira, A.Z. Saccol, J. Moscarola, "O método de pesquisa Survey", Revista de Administração da USP, vol. 35, pp. 105-112, Jul-Set 2000

[6] H. Lee, J.K. Lee, S. Park, I. Kim, "Translating building legislation into a computerexecutable format for evaluating building permit requirements", Automation in Construction, vol. 71, pp. 49-61, Novembro 2016. https://doi.org/10.1016/ j.autcon.2016.04.008

[7] H. Luo, P. Gong. "A BIM-based Code Compliance Checking Process of Deep Foundation Construction Plans", Journal of Intelligent \& Robotic Systems, vol. 79, pp.549-576, Outubro 2014. doi: https://doi.org/10.1007/s10846-014-0120-z

[8] J. Souza, A. Kern, B. Tutikian, "Análise quantiqualitativa da norma de desempenho (NBR $\left.\mathrm{N}^{\circ} 15.575 / 2013\right)$ e principais desafios na implantação do nível superior em edificação residencial de multipavimentos", Gestão e Tecnologia de Projetos, vol. 13, n. 1, pp. 127144, 2018. http://dx.doi.org/10.11606/gtp.v13i1.133842

[9] NBR 15.575, "Edificações Habitacionais - Desempenho", Associação Brasileira de Normas Técnicas, 2013

[10] P.S. Okamoto, "Os impactos da norma brasileira de desempenho sobre o processo de projeto de edificações residenciais", Tese de Mestrado, São Paulo, Escola Politécnica da USP, BRA, 2015.

[11] P. S. Visser, J. Krosnick, P. Lavrakas, N. Kim, Survey Research, in: H.T. Reis, C.M. Judd (eds), Handbook of Research Methods in Social and Personality Psychology. pp. 402-440, Cambridge: Cambridge University Press, 2014.

[12] S. Macit İlal, H. M. Günaydın, "Computer representation of building codes for automated compliance checking" Automation in Construction, vol. 82, pp. 43-58, Outubro 2017. http://dx.doi.org/10.1016/0010-4485(85)90287-8

[13] T. Bloch, M. Katz, R. Sacks, "Machine Learning approach for automated code compliance checking", in: 17th International Conference on Computing in Civil and Building Engineering (2018). Tampere, Finlândia, 2018. 